\title{
Influence of abutment material on the shade of dental implant restorations in the esthetic zone: a single case report
}

This article was published in the following Dove Press journal:

Clinical, Cosmetic and Investigational Dentistry

Osama A Qutub

Ghadeer I Basunbul

Abdulelah M Binmahfooz

Department of Oral and Maxillofacial Prosthodontics, Faculty of Dentistry, King Abdulaziz University, Jeddah, Saudi Arabia
Correspondence: Ghadeer I Basunbul 8317 Apartment 8, District Al-Marwah, Jeddah West 23545-5295, Saudi Arabia Tel +96 $6555595707 ;+966505675287$ Email gbasunbal@kau.edu.sa

\begin{abstract}
High esthetic demand and expectation challenges the rehabilitation of the esthetic zone with dental implants. Most implant system manufacturers offer customized and prefabricated ceramic, specifically zirconia or alumina abutments, as an alternative to titanium or gold alloy abutments, with the aid of computer-aided designing/computer aided manufacturing (CAD/CAM) technology. A 45-year-old male patient was referred to the prosthodontics clinic for the restoration of maxillary central incisors with all ceramic dental implants. After healing, both implants were restored with all-ceramic crowns but different customized abutment materials for the purpose of comparison. The all-ceramic crown was cemented on a customized zirconia abutment at the implant site \# 11 and on a customized gold alloy abutment at implant site \# 21. The treating dentist as well as two prosthodontists performed a meticulous clinical examination to compare the ceramic crowns side by side and agreed that the outcome was esthetically satisfactory. The patient was satisfied with the esthetics and functional outcome of the final restorations, as was the prosthodontist.
\end{abstract}

Keywords: dental implant abutments, esthetic outcome, zirconia abutment

\section{Introduction}

Implant supported restorations in partially edentulous patients have become a wellestablished treatment modality. Recently, single tooth therapy in the esthetic zone is a frequent indication for implant therapy. Numerous studies have reported similar implant survival and success rates for implants inserted in the esthetic zone as compared to those placed in other segments of the jaws. ${ }^{1-5}$ However, studies related to the objective and subjective outcome evaluation from an esthetic point of view are scarce. $^{6-12}$

High esthetic expectations challenge the rehabilitation of maxillary anterior teeth with implants as a result of the minimal thickness of the anterior maxillary alveolar ridge that requires hard and soft tissue grafting. ${ }^{13}$ The challenges are further amplified among patients with thin gingival biotype, high smile line, and limited mesiodistal space. Extraction and grafting of a non-restorable tooth performed as traditional anterior implant placement protocol requires a healing period of around 3-4 months. ${ }^{14,15}$ Prosthetic implant restoration must be carried out after a period of time that is essential for osseointegration. However, the immediate implant placement protocol, with or without simultaneous bone grafting, reduces total rounds of surgical procedures, increases patient compliance, and shortens the time of treatment. ${ }^{16}$ Removable, fixed tooth supported and implant-supported 
prostheses are likely to be used for obtaining provisionalized anterior implant site. ${ }^{17,18}$ However, removable and teeth supported fixed provisional restorations do not facilitate soft tissue maturation. ${ }^{15}$

Highly predictable esthetic outcomes are revealed from the establishment of therapeutic modalities and related materials while rehabilitating the esthetic zone of teeth. The esthetic outcomes have been improved with the development of ceramic oxide abutments, such as aluminum oxide and zirconium oxide, that possess higher strength than gold or titanium abutments. ${ }^{19}$

However, comparisons of zirconia, gold alloy, and titanium, and biological esthetic, patient, and mechanical subjective treatment of implant-related restorations are rare. The present case study reports the clinical steps for restoration of a dental implant with immediate provisional restoration, followed by implant-supported all-ceramic crowns with zirconia and gold abutments after completing osseointegration for objective and subjective esthetic outcome comparison.

\section{Case report}

A 45-year-old male patient was referred to the prosthodontics clinic to complete the restoration of a dental implant $(3.7 \mathrm{~mm} \times 11 \mathrm{~mm}$, Zimmer implant, Standard Plus, regular neck, Zimmer Dental, Carlsbad, CA, USA), at the site of tooth \#21. The dentist had placed an implant 3 months previously and then started the construction process of a cement-retained crown for restoring implant \#21 and fabricated a gold customized implant abutment. Before completion of the implant restoration, the patient was referred to our clinic to continue the treatment.

During the first visit, patient medical and dental history was reviewed. According to the American Society of Anesthesiologists (ASA) physical status classification system, the patient is ASA1. The patient's chief complaint was to continue the treatment of his anterior teeth. Upon smiling, the patient has a low to average smile line. The apparent teeth have a homogenous shade that the patient was satisfied with. Intraoral examination revealed adequate periodontal health, tooth \#11 had a provisional crown, and tooth \#21 is an implant with a healing abutment. The patient has thin gingival biotype. Radiographic examination displayed the current process of external root resorption for tooth \#11. The patient was provided with complete information regarding treatment options to make a decision for tooth extraction and implant placement of \#11 (Figure 1). The patient signed an informed consent to proceed with the treatment plan.

\section{Preparation}

The cone-beam computed tomography (CBCT) image for the patient displayed sufficient sound buccal, lingual, and apical alveolar bone around tooth \#11. A surgical guide was developed as a duplicate for the prior master cast for the prosthodontist with self-cure acrylic resin. The surgeon was guided through predetermined mesiodistal and buccolingual center channel for tooth extraction $\# 11$ in the patient's mouth. The implant mount attachment was facilitated with the help of an acrylic transfer jig to assure the cast fabrication for quick succession to fabricate the fixed dental prosthesis after placing an implant. In addition, the vacuum-formed template for provisional restoration fabrication was used for fabricating a $1.5 \mathrm{~mm}$ thermoplastic material.

\section{Immediate implant placement}

The surgical process was performed by the periodontist by giving local anesthesia to the patient. Tooth \#11 was removed by performing flapless and atraumatic extraction, followed by normal socket saline rinsing, debridement, and curettage. In addition, during implant drilling, the mouth of the patient was secured through the teeth-supported surgical guide. By using the standard protocols for the Zimmer system, implant placement and bone preparation were

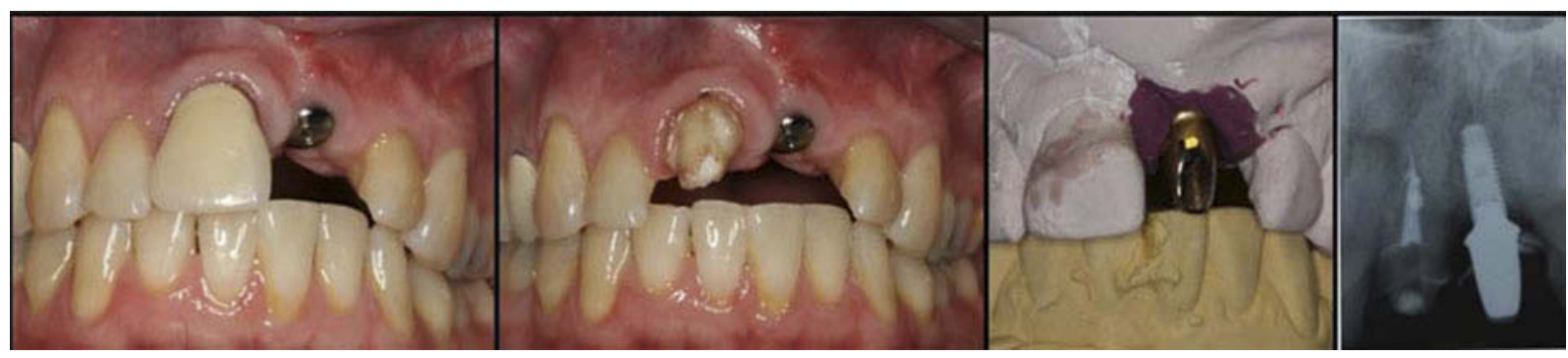

Figure I Non-restorable tooth \#II due to ongoing external root resorption. 


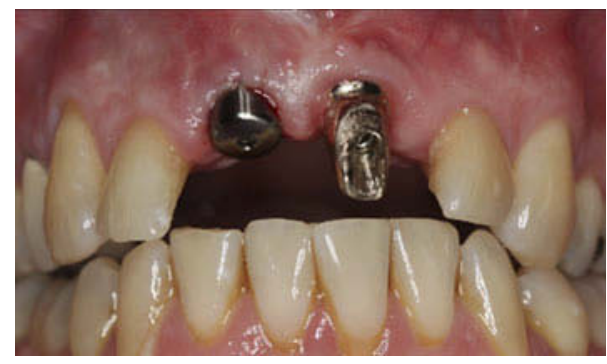

Figure 2 Immediate implant placement.

performed in the patient's mouth. The placement and torquing of a Zimmer implant were ensured at $40 \mathrm{~N} \mathrm{~cm}$ (Figure 2). In contrast, there was no essential requirement made by the dentist toward soft tissue suturing.

\section{Provisional restoration}

After the implant placement, the transfer jig was secured on the adjacent teeth and the implant mount was carefully connected to the jig by adding autopolymerizing acrylic resin. The implant mount was retrieved from the patient mouth with the attached jig, screwed to an implant lab analog and then transferred to the cast. Two implant temporary abutments from Zimmer (Zimmer Dental, Carlsbad,
Calif) were placed on the cast and prepared using the clear vacuum-formed shell template (Figure 3).

The implant supported fixed provisional restoration was constructed to develop the preferred emergence profile using acrylic resin. The provisional fixed dental prostheses were appropriately finished and polished.

The temporary abutments were screwed to the implants in the patient's mouth, and Teflon tape was used to block both temporary abutments' access holes. Afterward, the minimum amount of non-eugenol temporary cement was used to cement the provisional restoration and excess cement was safely removed. Occlusion was adjusted to ensure minimal contacts during eccentric and centric occlusion (Figure 4).

Post-operative instruction was given to the patient and recall visits were done after 7 days, 4 weeks, 8 weeks, 12 weeks, and 16 weeks. On each follow-up appointment, the healing was assessed with no signs of inflammation or infection. Also, the development of the soft tissue emergence profile around the implant was monitored and the provisional restoration was adjusted if required. Esthetics and phonetics were evaluated and the patient displayed a complete satisfaction with the outcome (Figure 5).

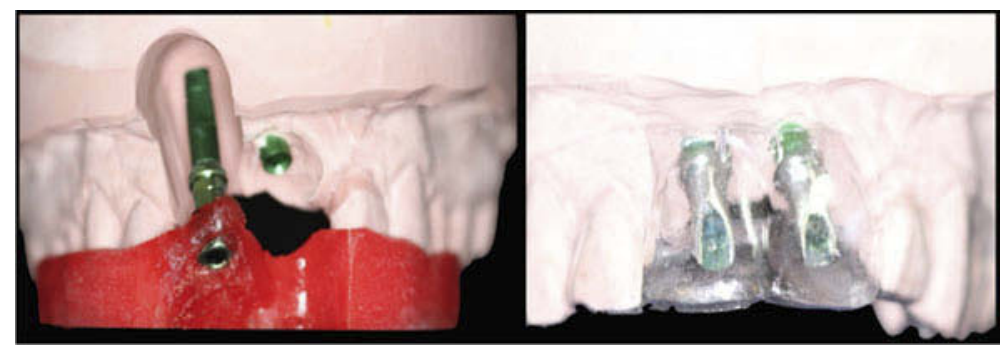

Figure 3 Implant temporary abutments placed on the casts.

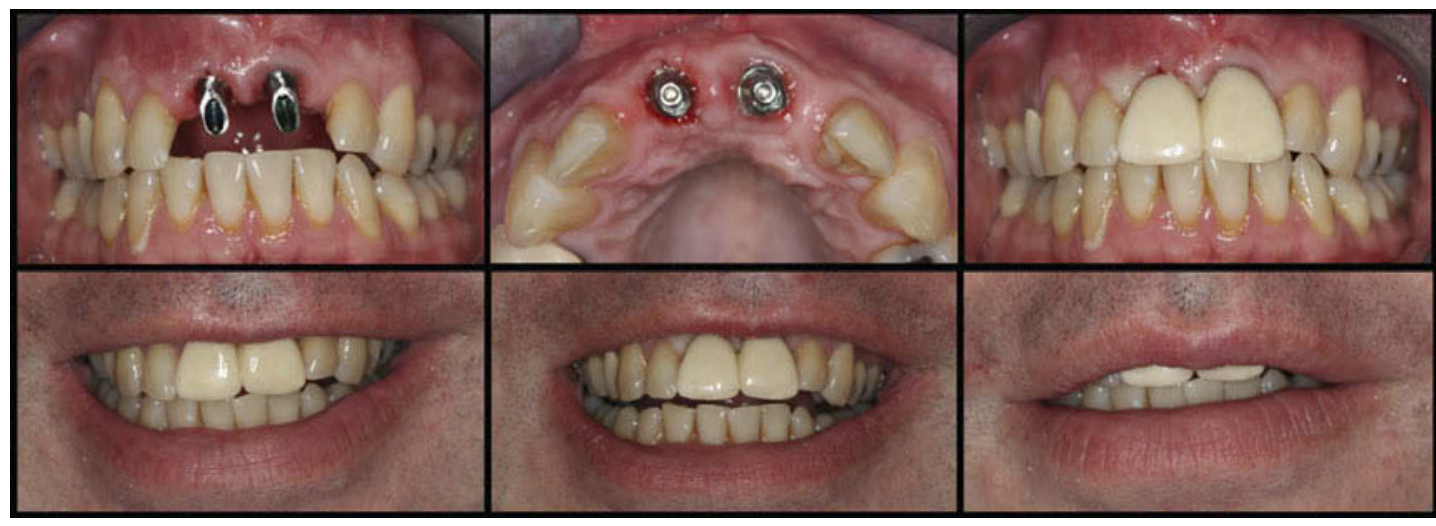

Figure 4 Implant supported provisional fixed dental prosthesis. 


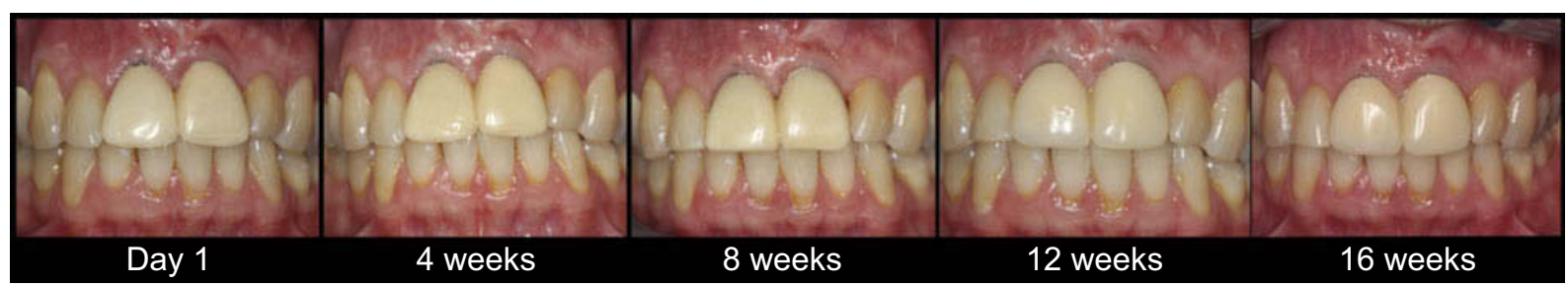

Figure 5 Evaluation of esthetics and phonetics on visits at first day, 4 weeks, 8 weeks, 12 weeks, and 16 weeks.

\section{Final restoration}

A definitive open tray impression was done by using Impergum Penta-Soft after 4 months of healing (Figure 6). The customization of impression copings was based on the transference of the emergency profile of the soft tissue. ${ }^{20}$ The soft tissue emergence profile was transferred to the mastercast using light body polyvinyl siloxane material (Figure 7).

Full contour wax up was made for crowns \#11 and 21 on the master cast. The clear vacuum-formed shell template was used to adjust the old gold custom abutment of implant \#21. Afterward, mounted master casts, gold abutment $\# 21$, and the clear template were sent to Astra Tech (Mölndal, Sweden) to design and fabricate a customized milled CAD/CAM Atlantis abutment. Abutment design of implant \#11 was requested to match the design of gold abutment \#21 except in material. The abutment designed for implant \#11 was fabricated from zirconia for comparison purposes. An approval from the prosthodontists was taken via email for the abutment design (Figure 8). A one-piece customized abutment which consisted entirely of zirconia was milled and shipped to the clinic.
Upon arrival, both abutments were checked on the cast for exact duplication. Full contour acrylic resin crowns were constructed on both abutments to confirm the equal thickness of both crowns on all sections. Thickness evaluation was made using a polygauge and all the readings were equal on both crowns in all sections (Figure 9).

Next, crowns with porcelain fused to zirconia were constructed for implant abutments \#11 and \#21. Again, the buccal thicknesses of the final crowns were measured and compared using a polygauge. All readings were comparable for both crowns (Table 1). Afterward, abutments were screwed to both implants and final crowns were checked in the patient's mouth to evaluate esthetics and phonetics. Shade evaluation of both crowns was carried out by the treating prosthodontist on their buccal surfaces (incisor, middle, and cervical thirds) using VITA Easyshade Advance System (VITA Zahnfabrik, H. Rauter GmbH \& Co. KG, Bad Säckingen, Germany). All readings were comparable in relation to CIE L*a*b* color space, Classical Vita Shade Guide and 3D Master Shade Guide. The shades of both crowns were comparable and rated clinically satisfactory by the treating prosthodontist and patient. Finally, customized

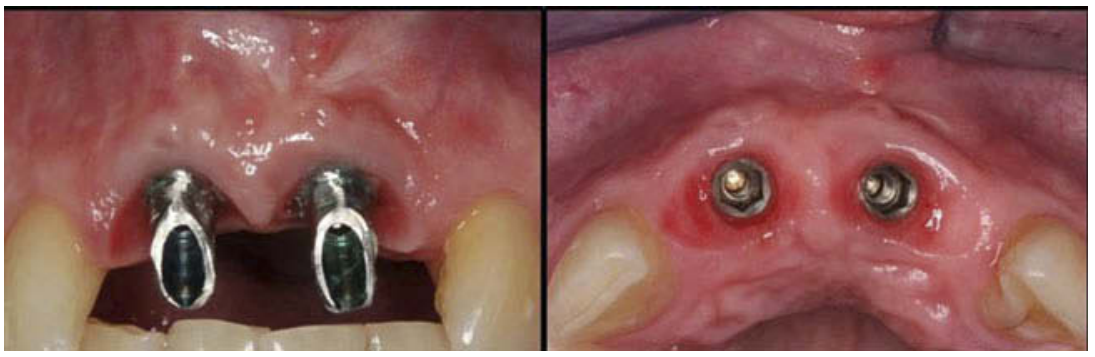

Figure 6 Soft-tissue maturation at the time of impression taking.

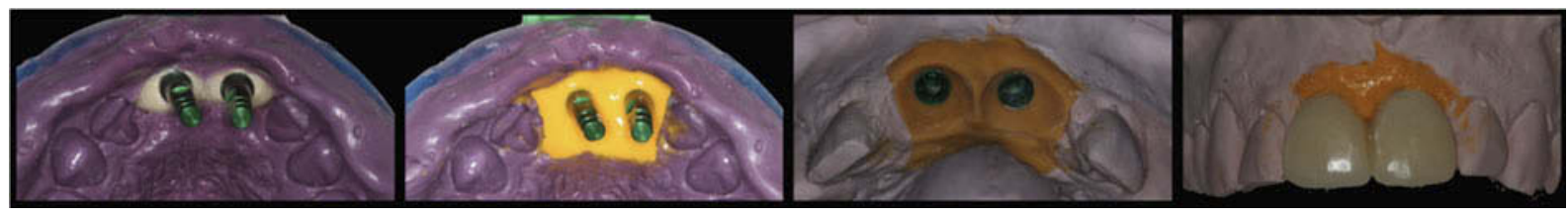

Figure 7 Definitive impression using customized impression coping and impergum impression material to transfer the emergence profile to the master cast. 


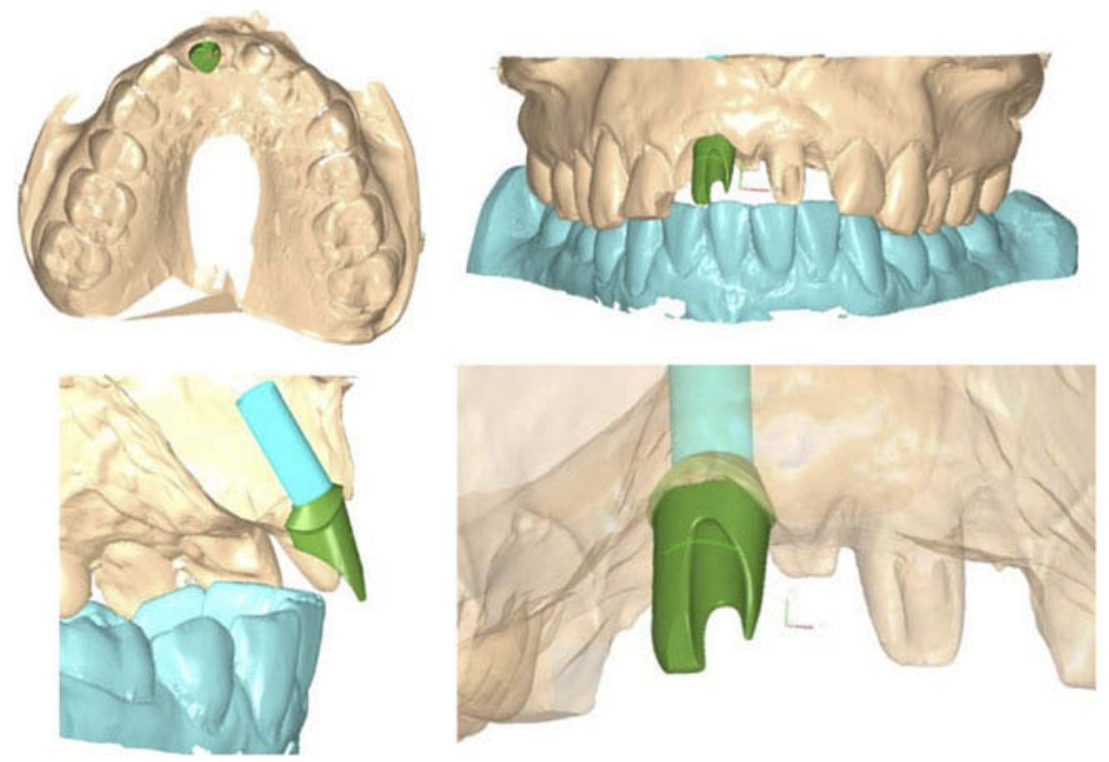

Figure 8 Customized zirconia abutment.

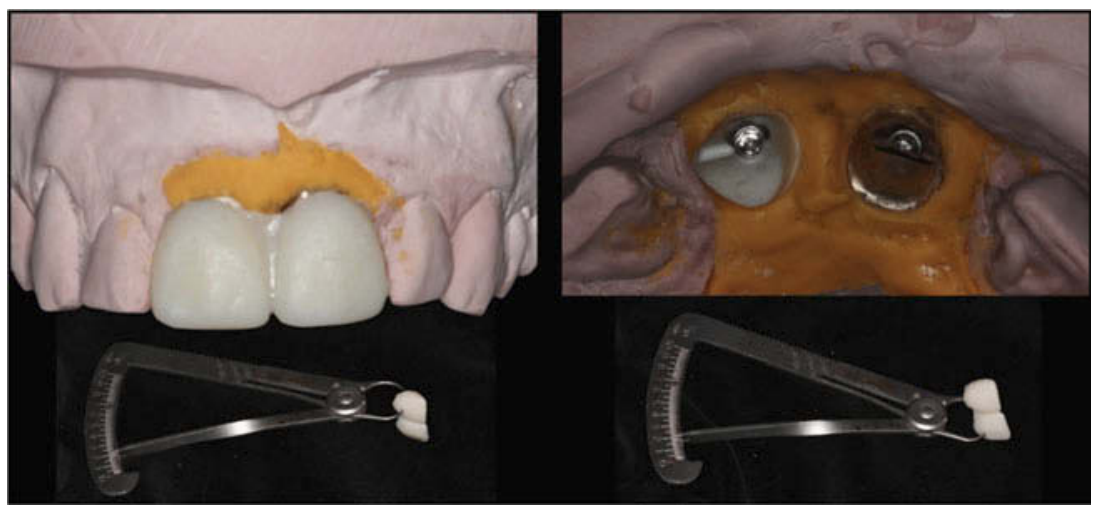

Figure 9 Abutments' thickness evaluation using apolygauge.

Table I Easyshade advance system readings for implant supported crown \#II and \#2I

\begin{tabular}{|l|l|l|l|l|l|}
\hline & b* & $\mathbf{a}^{*}$ & L* & Basic & 3D \\
\hline Crown \#II & & & & & \\
Cervical & 27 & -1.4 & 85.3 & A3 & $2 \mathrm{M} 2$ \\
Middle & 25.1 & -0.6 & 83.9 & A2 & $2 \mathrm{M} 2$ \\
Incisal & 10.9 & -3.5 & 90.3 & BI & $2 \mathrm{MI}$ \\
\hline Crown \#2I & & & & & \\
Cervical & 26.5 & -1.2 & 87.1 & A3 & $2 \mathrm{M} 2$ \\
Middle & 24.7 & -0.7 & 84.2 & A2 & 2M2 \\
Incisal & 21.6 & -2.9 & 85.9 & B2 & IM2 \\
\hline
\end{tabular}

abutments were torqued to $30 \mathrm{~N} \mathrm{~cm}$, access hale were blocked with Teflon tape, and the final crowns were cemented with non-eugenol temporary cement (Temp Bond NE, Kerr; Orange, CA, USA) (Figure 10).
Two experts in fixed prosthodontics who had not taken part in the patients' treatment performed the clinical evaluation. Both observers had good eyesight that will assist in comparing the esthetic appearance of both implants supported all-ceramic crowns with gold and zirconia abutment side by side. Variations were detected using artificial diffuse light and the Vita 3D Master shade guide by standing $50 \mathrm{~cm}$ from the mouth of the patient where the head of the patient was positioned upright. There was no difference observed in the color aspect by prosthodontics.

\section{Patient recall}

The recall visits were done after 2 weeks, 1 month, 3 months, and 1 year from delivery of final restorations. Both implants and their restorations were assessed. The 


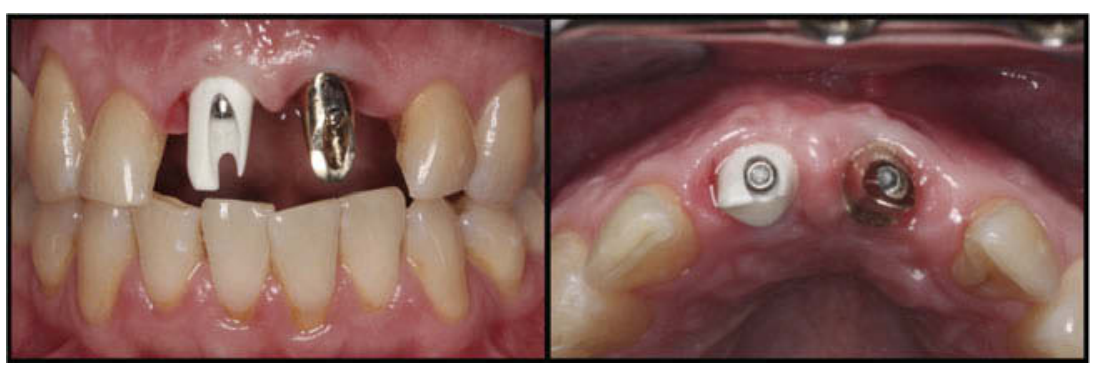

Figure 10 Final crowns cemented with temporary cement.

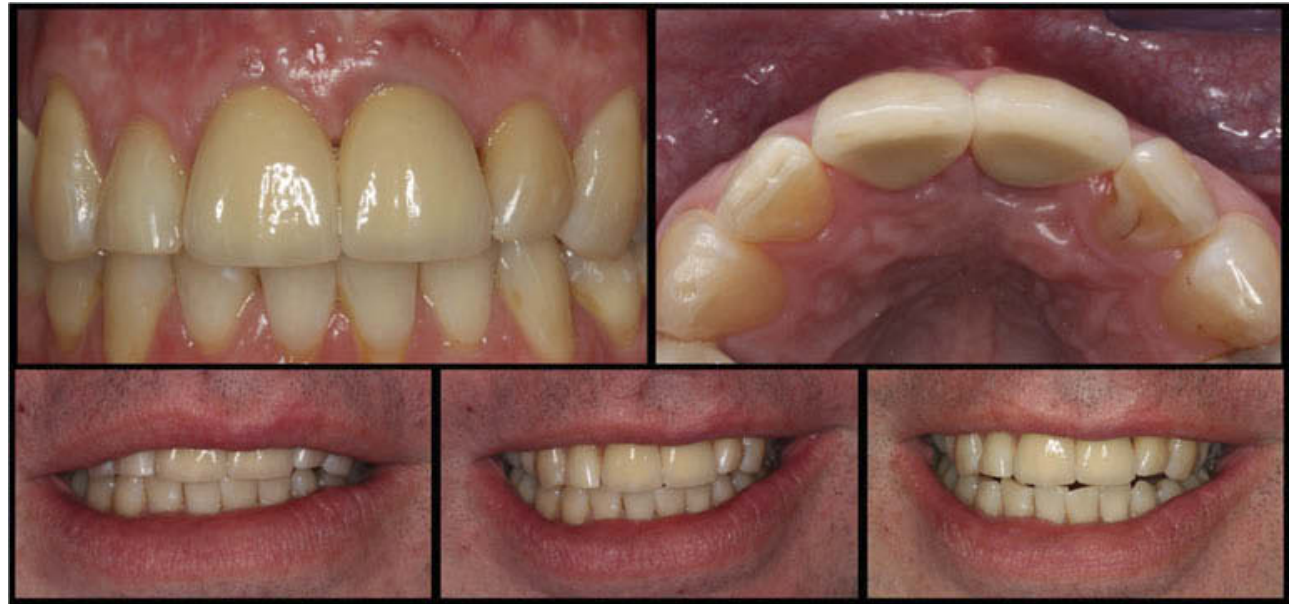

Figure I I Final picture of teeth restoration.

patient was satisfied with the esthetics and functional outcome of the final restorations, as was the prosthodontist (Figure 11). A written informed consent has been provided by the patient to have the case details and accompanying images published. The institution allowspublicationof the patient's treatment and images for scientific purposes.

\section{Discussion}

Ideal restoration of the teeth can be developed by restoring the natural contours of extracted teeth. The successful result of restoration has shown the significance of early initiation of soft tissue contouring when extraction, implant placement, and immediate provisionalization were performed simultaneously (Figure 11). ${ }^{21-23}$ The impressions for the definitive restoration were made using customized impression copings after complete osteointegration of the implant and maturation of soft tissue contours. The copings had the ability to capture the molded contours of soft tissues that surround the implant. ${ }^{20,24,25}$ Other techniques that have been reported to accurately transfer the mature peri-implant soft tissue profile include the use of the provisional restoration as impression coping, the injection of impression material around the provisional restoration seated on the master cast and fabricating an emergence profile cast. ${ }^{26}$

Mechanical and biological advantages for using zirconia abutment were demonstrated in the clinical studies regarding the fabrication of implant support restoration. Appropriate conditions were prompted through zirconia abutment for soft tissue healing. In contrast, there were insignificant differences reported between plaque indexes and bleeding on probing, bacterial adhesion and pocket depth between gold and zirconia implant abutments. Moreover, superior physical and mechanical properties characterize zirconium oxide compared to other available ceramics. In addition, radiographic visualization is assisted through zirconia abutment due to its higher radiopacity. However, the zirconia customization is more timeconsuming and demanding. The use of manufacturing technology or computer-aided design in zirconia abutment fabrication is essential. Thereby, there is an increase in the overall cost but it is acceptable when compared to the increasingly higher price of gold. Moreover, an additional clinical attempt before the fabrication of the final crown is required. A bright appearance of the final restoration can 
result from the white color inherent in zirconia. The surfaces can be colored with a subsequent veneering ceramic material to equalize the natural dentition in such cases. Proper design of the definitive restoration is ensured through positive lasting prognosis because customized abutment is used for the fabrication. ${ }^{27,28}$

\section{Conclusion}

The presented case report compared the esthetic outcome of all-ceramic implant-supported restorations replacing both maxillary central incisors side by side. One central incisor was restored by an all-ceramic crown cemented to a customized gold alloy abutment and the other all-ceramic crown was cemented to a customized zirconia abutment. Both abutments had similar dimensions and design. The esthetic outcome of both crowns resulted in satisfactory results to the patient and experts.

\section{Acknowledgments}

The authors are very thankful to all the associated personnel in any reference that contributed in/for the purpose of this research. This research is not funded through any source.

\section{Disclosure}

The authors declare no conflicts of interest in this work.

\section{References}

1. Eckert SE, Wollan PC. Retrospective review of 1170 endosseous implants placed in partially edentulous jaws. J Prosthet Dent. 1998;79:415-421.

2. Lindh T, Gunne J, Tillberg A, Molin M. A meta-analysis of implants in partial edentulism. Clin Oral Implants Res. 1998;9:80-90.

3. Wyatt CC, Zarb GA. Treatment outcomes of patients with implant-supported fixed partial prostheses. Int $J$ Oral Maxillofac Implants. 1998;13:204-211.

4. Noack N, Willer J, Hoffmann J. Long-term results after placement of dental implants: longitudinal study of 1,964 implants over 16 years. Int J Oral Maxillofac Implants. 1999;14:748-755.

5. Naert I, Koutsikakis G, Duyck J, Quirynen M, van Steenberghe D, Jacobs R. Biologic outcome of implant-supported restorations in the treatment of partial edentulism. Part I: a longitudinal clinical evaluation. Clin Oral Implants Res. 2002;13:381-389.

6. Vilhjálmsson VH, Klock KS, Størksen K, Bårdsen A. Aesthetics of implant-supported single anterior maxillary crowns evaluated by objective indices and participants' perceptions. Clin Oral Implants Res. 2011;22(12):1399-1403. doi:10.1111/j.1600-0501.2010.02128.x

7. Akoğlu Vanlığlu B, Kahramanoğlu E, Yıldız C, Özkan Y, KulakÖzkan Y. Esthetic outcome evaluation of maxillary anterior single-tooth bone-level implants with metal or ceramic abutments and ceramic crowns. Int J Oral Maxillofacial Implants. 2014;29:5.

8. Gallucci GO, Grütter L, Nedir R, Bischof M, Belser UC. Esthetic outcomes with porcelain-fused-to-ceramic and all-ceramic singleimplant crowns: a randomized clinical trial. Clin Oral Implants Res. 2011;22(1):62-69. doi:10.1111/j.1600-0501.2010.01997.x
9. Albashaireh ZS, Alhusein AA, Marashdeh MM. Clinical assessments and patient evaluations of the esthetic quality of maxillary anterior restorations. Int J Prosthodont. 2009;22(1).

10. Douglas RD, Brewer JD. Acceptability of shade differences in metal ceramic crowns. J Prosthet Dent. 1998;79(3):254-260.

11. Belser UC, Schmid B, Higginbottom F, Buser D. Outcome analysis of implant restorations located in the anterior maxilla: A review of the recent literature. Int $J$ Oral Maxillofac Implants. 2004;19 (Suppl.):30-42.

12. Martin WC, Morton D, Buser D. Diagnostic factors for esthetic risk assessment. In: Buser D, Belser U, Wismeijer D, editors. ITI Treatment Guide, Vol. 1: Implant Pink and White Esthetic Scores in Anterior Implants Volume $80 \bullet$ Number 1150 Therapy in the Esthetic Zone - Single-Tooth Replacements. Berlin: Quintessence Publishing; 2006:11-20.

13. Schoenbaum TR, Klokkevold PR, Chang YY. Immediate implant supported provisional restoration with a root-form pontic for the replacement of two adjacent anterior maxillary teeth: a clinical report. J Prosthet Dent. 2013;109:277-282. doi:10.1016/S0022-3913(13)00086-3

14. Prasad S, Banez JD, Bompolaki D, Hart Y. Optimizing anterior implant outcome immediately after implant placement and grafting by using patient's extracted teeth: a case report. J Dent Oral Biol. 2017.

15. Esposito M, Grusovin MG, Polyzos IP, Felice P, Worthington HV. Interventions for replacing missing teeth: dental implants in fresh extraction sockets (immediate, immediate-delayed and delayed implants). Cochrane Database Syst Rev. 2010;2:CD005968.

16. Schoenbaum TR, Han TJ. Direct custom implant impression copings for the preservation of the pontic receptor site architecture. J Prosthet Dent. 2012;107:203-206.

17. Margeas RC. Predictable periimplant gingival esthetics: use of the natural tooth as a provisional following implant placement. $J$ Esthet Restor Dent. 2006;18:5-12.

18. Atieh MA, Payne AG, Duncan WJ, Cullinan MP. Immediate restoration/loading of immediately placed single implants: is it an effective bimodal approach? Clin Oral Implants Res. 2009;20:645-659. doi:10.1111/j.1600-0501.2009.01725.x

19. Sailer I, Zembic A, Jung RE, Hämmerle CH, Mattiola A. Singletooth implant reconstructions: esthetics factors influencing the decision between titanium and zirconia abutments in anterior regions. Eur $J$ Esthet Dent. 2007;2:3.

20. Hinds KF. Custom impression coping for an exact registration of the healed tissue in the esthetic implant restoration. Int $J$ Periodont Restor Dent. 1997;17:6.

21. Kois JC. Predictable single tooth peri-implant esthetics: five diagnostic keys. Compend Contin Educ Dent. 2001;22(3):199-206.

22. Garber DA, Salama MA, Salama H. Immediate total tooth replacement. Compendium. 2001;22(3):210-218.

23. Wöhrle PS. Single-tooth replacement in the aesthetic zone with immediate provisionalization: fourteen consecutive case reports. Practl Periodont Aesthet Dent. 1998;10(9):1107-110714.

24. Buskin R, Salinas TJ. Transferring emergence profile created from the provisional to the definitive restoration. Practl Periodont Aesthet Dent. 1998;10(9):1171-1179.

25. Stumpel LJ, Haechler W, Bedrossian E. Customized abutments to shape and transfer peri-implant soft-tissue contours. $J$ Calif Dent Assoc. 2000;28(4):301-309.

26. Elian N, Tabourian G, Jalbout ZN, et al. Accurate transfer of periimplant soft tissue emergence profile from the provisional crown to the final prosthesis using an emergence profile cast. J Esthet Restor Dent. 2007;19(6):306-314. doi:10.1111/j.1708-8240.2007.00128.x

27. Glauser R, Sailer I, Wohlwend A, Studer S, Schibli M, Schärer P. Experimental zirconia abutments for implant-supported single-tooth restorations in esthetically demanding regions: 4-year results of a prospective clinical study. Int J Prosthodont. 2004;17:3.

28. Nakamura K, Kanno T, Milleding P, Örtengren U. Zirconia as a dental implant abutment material: a systematic review. Int $J$ Prosthodont. 2010;23:4. 


\section{Publish your work in this journal}

Clinical, Cosmetic and Investigational Dentistry is an international, peer-reviewed, open access, online journal focusing on the latest clinical and experimental research in dentistry with specific emphasis on cosmetic interventions. Innovative developments in dental materials, techniques and devices that improve outcomes and patient satisfaction and preference will be highlighted. The manuscrip management system is completely online and includes a very quick and fair peer-review system, which is all easy to use. Visit http://www.dovepress.com/testimonials.php to read real quotes from published authors.

Submit your manuscript here: https://www.dovepress.com/clinical-cosmetic-and-investigational-dentistry-journal 